\title{
NOVAS RELAÇÕES DE TRABALHO: UM ESTUDO SOBRE PSICÓLOGOS QUE ATUAM COMO PROFISSIONAIS LIBERAIS VINCULADOS A UMA INSTITUIÇÃO
}

\begin{abstract}
Resumo
O artigo enfoca novas relações de trabalho nas quais o emprego fixo está deixando de ser o padrão, abrindo espaço para formas diferenciadas de contratação. Estuda o caso do Instituto Brasileiro de Psicanálise, Dinâmica de Grupo e Psicodrama (SOBRAP) Juiz de Fora. Realizou-se uma revisão da literatura sobre a evolução das relações de trabalho, bem como uma pesquisa de campo com a aplicação de questionários, objetivando conhecer a visão dos psicólogos sobre seu próprio desempenho e o dos colegas de trabalho. Conclui-se que adequações devem ser realizadas na instituição, para que os profissionais estejam satisfeitos, desempenhando assim melhor sua função.
\end{abstract}

Palavras-chave: Gestão de pessoas. Relações de trabalho. Profissionais liberais.

\section{NEW LABOR RELATIONS: A STUDY ON PSYCHOLOGISTS ACTING AS LIBERAL PROFESSIONALS LINKED TO AN INSTITUTION}

\begin{abstract}
The article focuses on new working relationships in which the permanent job is no longer the standard, making room for different forms of engagement. Studies the case of the Brazilian Institute of Psychoanalysis, Group Dynamics and Psychodrama (SOBRAP) Juiz de Fora. We conducted a literature review on the evolution of labor relations, as well as a field survey with questionnaires, aiming to meet the vision of psychologists about their own performance and that of colleagues. We conclude that adjustments should be made in the institution, so that professionals are satisfied, thus performing its function better.
\end{abstract}

Keywords: Work. Professional Liberal. Psychologists.

\footnotetext{
Psicóloga com Pós-Graduação em Gestão Estratégica de Pessoas pela UFJF (saritinha_@hotmail.com)

2 Doutor em Administração e Mestre em Administração Pública pela FGV/EBAPE. É professor Adjunto da Faculdade de Administração e Ciências Contábeis da Universidade Federal de Juiz de Fora (FACC/UFJF). (victorclaudio@uol.com.br)

3 Professora da Universidade Federal de Juiz de Fora (debora1@powermail.com.br)
} 


\section{Introdução}

O presente artigo tem como objetivo compreender as relações de trabalho sem base em vínculo tradicional, analisando especificamente o caso da organização escolhida para o estudo, o Instituto Brasileiro de Psicanálise, Dinâmica de Grupo e Psicodrama (SOBRAP) Regional Juiz de Fora. A relação mencionada refere-se aos profissionais liberais que atuam no centro de atendimento dessa entidade e que não possuem contrato de trabalho com carteira assinada. Embora o foco esteja especificamente nesse caso, é certo que as indagações que deram origem à pesquisa se revelam importantes para outras instituições e outros profissionais liberais.

Atualmente, nota-se o progressivo aumento da atuação de profissionais liberais vinculados a organizações, abrindo espaço desta maneira para relações de trabalhos diferenciadas das tradicionais. Os profissionais liberais (no caso, os psicólogos clínicos) manifestam que sentem dificuldades no que se refere às condições de trabalho em sua área de atuação.

Os investimentos na carreira, através de estudos e cursos, são importantes para o desenvolvimento de um bom trabalho. Porém, os gastos em aperfeiçoamento nem sempre são compensados em termos de benefícios, podendo gerar frustração. No tipo de trabalho citado, em casos no qual o profissional liberal não presta serviço como empregado na instituição, alguns direitos trabalhistas e previdenciários são extintos, como: salário mensal fixo, décimo terceiro, férias (sem interferir nos benefícios), adicional de férias, fundo de garantia, hora extra e adicional noturno. Portanto, é um caminho onde a instabilidade é maior e os benefícios sociais são menores.

Quando o trabalho é realizado dentro de uma clínica, além do vínculo estabelecido com o paciente, existe a relação com os demais profissionais que atuam na organização. Portanto, os papéis devem ser bem estabelecidos para a realização de um bom trabalho e a manutenção de um convívio saudável. Observa-se, neste sentido, a importância da existência de um supervisor coordenando os profissionais liberais. Entretanto, percebe-se que essa função é desafiadora, pois embora os profissionais sejam parte da instituição, permanecem como profissionais liberais.

A SOBRAP-JF, que começou suas atividades em 1979 e contava no momento da pesquisa com um total de 56 membros associados. Os serviços ofertados são prestados por profissionais liberais, porém vinculados à SOBRAP-JF por meio dos estudos de formação. São utilizadas como base, teorias da Psicanálise, Dinâmica de Grupo e/ou Psicodrama. Os atendimentos psicoterapêuticos são realizados com crianças, adolescentes, adultos, $3^{\mathrm{a}}$ idade, casal e família. O atendimento pode ser feito individualmente ou em grupo.

Partindo da constatação de que existem necessidades diferenciadas de supervisão, em função do tipo de relação trabalhista verificado, o artigo aqui apresentado tem como foco a seguinte questão central:

Quais os principais desafios enfrentados pelos profissionais liberais (psicólogos) do centro de atendimento da SOBRAP, Regional Juiz de Fora?

Assim, a obtenção de respostas sobre esta situação se faz importante para o entendimento e o desenvolvimento de uma relação satisfatória no ambiente de trabalho entre os profissionais liberais, pacientes e os demais funcionários.

O artigo está dividido em cinco seções, contando com esta introdução. Na próxima, é apresentado o percurso metodológico percorrido. Nas seguintes, a revisão da literatura, os resultados dos dados obtidos na pesquisa de campo e as considerações finais. 


\section{Metodologia}

Partindo do objetivo exposto na introdução, foi adotado o método de abordagem indutivo e de natureza qualitativa para a coleta de informações na organização. Conforme relata Minayo (2003), a pesquisa qualitativa tem como princípio norteador a verificação da ciência social em uma dada realidade. Entretanto, é um tipo de pesquisa que não pode ser medida de forma quantitativa por fazer referência a valores, crenças, construção e relação. Segundo Godoy (1995), esta pesquisa possui foco na compreensão dos fenômenos expostos pelos participantes do estudo, análise dos dados feita indutivamente, o ambiente, caráter descritivo, o processo e não o resultado. A utilização do método indutivo torna-se cabível neste estudo mediante a explicação de Rudio (1998), pelo fato de observar circunstâncias em que as causas são desconhecidas. Consecutivamente, há a investigação da relação entre circunstância e causa e, finalmente, uma generalização entre relação e fatores verificados com a pesquisa.

Com base na taxonomia proposta por Gil (2002), o tipo de pesquisa pode ser classificado quanto aos objetivos e aos procedimentos técnicos. Assim, a pesquisa aqui apresentada pode ser considerada descritiva, por ter como meta principal o levantamento de dados sobre um grupo de psicólogos (profissionais liberais) no tocante a condições/regras para a realização de seus serviços na SOBRAP Regional Juiz de Fora, o vínculo com os colegas de trabalho, com os pacientes e com a própria instituição. Abordando estes aspectos, torna-se possível averiguar as principais dificuldades enfrentadas nesta nova relação de trabalho. O procedimento técnico utilizado foi o estudo de campo, haja vista que uma realidade específica foi abordada com levantamento de informações no local onde os fenômenos acontecem. Também foi realizado um estudo bibliográfico que, como destacam Marconi \& Lakatos (1996), auxilia o pesquisador a enriquecer seus conhecimentos sobre o assunto que se pretende investigar. A revisão da literatura serviu, também, para respaldar a definição dos objetivos da pesquisa, hipóteses, universo, amostra, meio de coleta de dados, tabulação e análise.

As entrevistas foram direcionadas para os psicólogos que atuam no Centro de Atendimento da organização estudada. Dos 22 sujeitos que trabalhavam na instituição no momento da pesquisa, 18 profissionais participaram da coleta de dados.

O instrumento selecionado para o levantamento de dados foi o questionário misto, contemplando questões abertas e outras fechadas, considerado o mais indicado neste tipo de trabalho. O uso desse questionário visou, além do recolhimento de dados pelas questões fechadas, a obtenção de considerações feitas pelos participantes acerca do assunto pesquisado. Os questionários foram aplicados e respondidos por e-mail. $O$ tratamento dos dados coletados foi efetuado com o auxílio da Escala de Likert. De acordo com Martins (2006), com a utilização dessa escala é possível coletar indicadores sobre as questões abordadas na pesquisa, avaliando a concordância ou discordância do participante em cada resposta. O critério adotado para a tabulação teve como base a determinação do grau de relevância de cada fator apontado, em uma escala de 1 a 4, na qual "1" representa forte discordância e "4" forte concordância, sendo "2" e "3" graus intermediários. Em parte das questões, foram solicitadas duas diferentes respostas: uma auto-avaliação do pesquisado e depois uma avaliação do grupo de colegas.

Como salienta Vergara (2009), qualquer método possui possibilidades e limitações. Tornase importante, assim, ressaltar as principais limitações verificadas. A pesquisa foi efetuada destacando a situação específica da instituição. Sendo assim, não cabe estender os resultados a outras organizações. Também deve ser ressalvado que o estatuto seguido no centro de atendimento foi modificado poucos dias antes da pesquisa de campo ser realizada. Sendo esse um documento de expressiva importância para as relações de trabalho, as mudanças verificadas poderão impactar os resultados de pesquisas similares a esta que venham a ser desenvolvidas. Cabe ressaltar ainda o fato de que as respostas foram identificadas, por 
terem sido enviadas por e-mail, o que pode ter gerado dificuldade ou constrangimento ao transparecer alguma crítica à instituição.

Como ocorre em qualquer pesquisa qualitativa por amostragem não probabilística e restrita a uma organização, os resultados alcançados representam o ponto de vista dos profissionais que responderam o questionário, não podendo ser encarados como verdade absoluta para toda a categoria, haja vista que, as opiniões podem divergir, cabendo o respeito à subjetividade de cada profissional.

\section{A comunicação corporativa: natureza e importância}

Segundo Rodrigues Y Rodrigues (2001), a mudança é um processo presente continuamente na vida do indivíduo e a este cabe buscar meios para se adaptar ao cenário das transformações. Tal modificação é aplicada em diferentes contextos da evolução e vivência, incluindo o mercado de trabalho. Quando imposto um padrão rígido ou inflexível para a realização do trabalho, o ser humano pode criar conflitos internos e manifestar o que se denomina rigidez de paradigmas. Os paradigmas passam pela via da percepção, representando uma espécie de filtro que distingue se a condição de trabalho corresponde à experiência pessoal, profissional e princípios éticos do trabalhador fora da rotina de trabalho. Tal fato pode acarretar conflitos internos e um desempenho insatisfatório em sua função, por seguir o modelo aprendido internamente e pela dificuldade em adaptar-se às regras da organização.

A evolução da sociedade influencia diretamente na mudança das relações de trabalho e no modo de produção. Assim, o advento da Revolução Industrial fez com que, conforme destaca Hobsbawn (2009), surgisse uma nova organização do trabalho, bastante distinta dos arranjos anteriormente vivenciados. No cenário que então despontou, as fábricas, máquinas, o sistema fabril e a energia motriz ganharam espaço. Em decorrência, as ferramentas, o campo e o trabalho braçal humano perderam força no mercado. Durante a Revolução Industrial, os trabalhadores ficavam durante muitas horas dentro das fábricas e realizavam uma jornada de trabalho excessiva. Entretanto, os operários passaram para a condição de assalariados e o trabalho era visto de forma separada do capital e dos meios de produção.

Cabe destacar também a primeira metade do século XX, período marcado pelo Taylorismo/ Fordismo na área industrial, devido às modificações ocasionadas pela inflexibilidade na forma de produção. Tais modelos apresentavam características em comum: o aumento da produção e do lucro em tempo pequeno e o trabalho realizado manualmente de forma racional, exigindo assim grande força física por parte dos operários. Neto (1991) ressalta a notória separação entre o trabalho mental (intelectual) e o trabalho braçal, destacando que os operários podiam desenvolver apenas o segundo tipo de trabalho. Não tinham o direito de compartilhar ideias, de expor a criatividade nem de opinar ou participar no desenvolvimento industrial, haja vista que, a função deles era restrita na produção e eram empregados apenas pela força física, o conteúdo intelectual não era valorizado ou levado em consideração no quadro de operários.

A era industrial começou a perder espaço quando a necessidade da força física deixou de ser a única condição para o desenvolvimento satisfatório das funções. Assim, começa a era pós-industrial, abrindo espaço para informação, comunicação e conhecimento serem utilizados no contexto dessas atividades. A economia, as novas tecnologias, e a comunicação embasaram esta nova era, pois o trabalho não era exercido mais com ênfase agrícola ou industrial e sim na produção de informações e serviços. Grandes transformações aconteceram, então. O trabalho intelectual passou a ser mais valorizado do que o manual e a criatividade mais reconhecida que a realização de tarefas automáticas (MASI, 2000).

Conforme destacam Zabot, Ardigo \& Salam (2001), pode-se afirmar que o processo de 
globalização está interligado às novas relações sociais estabelecidas no mercado de trabalho. Portanto, a partir desta colocação percebe-se a inviabilidade das instituições persistirem nos modelos anteriores em relação à forma de gestão, pois a concorrência e a necessidade de informação são crescentes, influenciando diretamente no comportamento dos indivíduos em suas atividades. Atualmente, é necessário que os trabalhadores desenvolvam seu potencial criativo e inovador para que alcancem satisfatoriamente a colocação almejada entre os competidores do ramo. "A globalização não significa apenas fazer negócios além das fronteiras nacionais. Significa também aumento da competição para quase todo tipo de organização" (ROBBINS, 2000, p. 6).

O termo globalização não possui um conceito específico, determinado como correto e nem está claro o local em que surgiu. De acordo com Hitt, Miller \& Colella (2007), o ritmo desse fenômeno está cada vez mais acelerado, em função, principalmente, do desenvolvimento dos meios de comunicação e da grande presença das companhias multinacionais no cenário econômico. Assim, percebe-se a necessidade de cada vez mais as pessoas se adaptarem em respeitar e trabalhar formando equipes com membros de países diferentes. O movimento da economia dita globalizada ocorre livremente nas fronteiras e o mercado de trabalho é visto como unificado.

Essas transformações foram fundamentais para uma série de medidas adotadas nos ambientes organizacionais. As mudanças passam pelo viés das relações de trabalho, vínculos empregatícios, remuneração, direitos trabalhistas, flexibilidade e jornada de trabalho. De acordo com Passos (1999), profundas mudanças surgiram no ambiente organizacional acompanhadas das dificuldades sofridas pelas empresas para se manterem atualizadas. As dificuldades se estendem também aos seus funcionários. Competência e responsabilidade passaram a ser exigidas em todos os níveis hierárquicos. Além disso, a qualidade dos serviços prestados é agora considerada essencial. Para atingir o resultado almejado é preciso comprometimento por parte de todos os setores.

As relações de trabalho são entendidas por Süssekind (2009) como o estabelecimento vincular entre duas partes. Exemplificando: um trabalhador que recebe seu pagamento através de uma pessoa física ou jurídica para qual prestou serviço. Entretanto, este tipo de conduta não se estende a profissionais liberais que trabalham dentro de instituições nas quais não são considerados empregados. Quando a organização não estabelece o contrato com hora fixa de trabalho, benefícios e carteira assinada não se configura uma relação de trabalho tradicional, mas nem por isso deixa de ser necessário seguir as regras institucionais.

Prux (1998) faz uma interessante distinção entre o profissional liberal e o profissional autônomo. Conceitua o profissional liberal por meio de uma categoria composta por indivíduos com formação acadêmica técnica ou com diploma de nível superior, possuidores de registro no conselho correspondente a cada profissão. O trabalhador autônomo por sua vez, não tem como exigência informação ou conhecimento comprovado em determinada área profissional, atuando de maneira independente.

Entretanto, analisando-se esse conceito, surge um importante questionamento: por que o trabalhador autônomo, mesmo não possuindo curso universitário, tem o direito de exercer uma profissão liberal? A modificação ocorreu através da emenda constitucional estabelecida na Constituição da República Federativa do Brasil de 1988, presente no artigo $7^{\circ}$ inciso 32 com a proibição em diferenciar estas duas categorias profissionais e ambos passam a ter o direito em ser assalariados (BRASIL, 2011). Porém, observando a prática, encontram-se diversas pessoas realizando serviços aprendidos com a prática e não comprovados por meio de certificados acadêmicos. São esses os profissionais autônomos, que na prática, diferem-se do profissional liberal por não atuar em atividades que necessitam de alto grau de responsabilidade. Caso o profissional liberal esteja desempenhando uma função diferente de 
sua formação, não será incluído nessa classe de trabalho. Deste modo, o trabalhador liberal possui habilitação para o exercício legal de uma profissão específica, sendo regulamentado por lei na maioria das vezes.

$\mathrm{Na}$ opinião de Vasconcelos (2003), os profissionais liberais são vistos como indivíduos que dedicaram certo tempo de estudo em determinada área acadêmica, passando a realizar um trabalho voltado especificamente para alcançar satisfação em sua área de formação. Ressalta ainda algumas características encontradas no cotidiano desses profissionais e fatores levados em consideração, a saber:

- Autonomia técnica: considera-se que o profissional liberal não deve ser subordinado por ordem de trabalho ou emprego, quando tal ordem existir deve ser jurídica. Isso porque o profissional presta seu serviço por conta própria independente do contexto que está inserido.

- Habilitação: para exercer suas atividades, o profissional liberal precisa estar habilitado para o exercício da função previamente.

- Habitualidade: refere-se à associação de hábitos entre o estilo de vida que o profissional possui juntamente com sua rotina da vida profissional.

- Presunção de onerosidade: torna-se necessário o profissional liberal conhecer como será efetuada sua remuneração para que possa programar suas despesas, haja vista, o fato de a remuneração mensal poder ser variável.

- Regulamentação: além do regulamento, há obrigatoriedade da normatização da atividade efetuada pelo profissional liberal.

- Vínculo à corporação ou sindicato: no caso de algumas profissões abrangendo principalmente o nível superior de ensino, torna-se fundamental o registro ao órgão correspondente à classe e/ou sindicato.

Para Nunes (2000), após a chamada era pós-moderna, o relacionamento entre o profissional liberal e seus clientes também se modificou. Antes, a confiança era vista como essencial para se escolher um profissional liberal. Em cada profissão, havia aqueles indicados que prestavam seus serviços, por exemplo, para todos os familiares de um cliente e o laço de amizade era feito. Este arranjo ocasionou o contrato denominado como intuitu personae, estabelecendo que as atividades pudessem ser realizadas unicamente pelo profissional liberal contratado. Hoje, este tipo de contrato não é o prevalecente no mercado de trabalho. As pessoas têm uma nova visão, buscam os serviços por meio dos planos de saúde/clínicas e não enxergam diferença entre o trabalho realizado pelo profissional liberal vinculado ou não a algum órgão. A partir dessa mudança, não cabe mais a afirmativa de que o relacionamento entre o profissional liberal e o contratante é um contrato intuitu personae.

O conceito de profissional liberal, como ressalta Diniz (2003), contempla a mudança da obrigação de o trabalhador ser habilitado em curso superior. O serviço prestado pelos profissionais liberais podem ser exercidos de maneira assalariada. Hoje, os profissionais liberais, por causa da economia e fatores sociais influenciados ativamente pela globalização, não se dedicam exclusivamente aos atendimentos em consultórios, pois não é garantia de estabilidade. Desta forma, a solução encontrada por parte dos profissionais foi associar-se a instituições nas quais tenham a possibilidade de obter remuneração estável e adquirir direitos garantidos nas leis trabalhistas. Sendo assim, mesmo o profissional liberal estabelecendo vínculo com alguma instituição, sua autonomia é preservada, pode se recusar a cumprir ordens caso estas não estejam coniventes à sua integridade ética e profissional.

É certo que existem vantagens e desvantagens no exercício de uma profissão liberal. São vantagens: trabalhar na área almejada, não dependendo de oportunidades oferecidas no mercado de trabalho e contar com uma flexibilidade maior na definição da jornada de trabalho, que é estipulada pelo próprio trabalhador. São desvantagens: remuneração instável 
(ainda que seja comprovado que muitos profissionais possuem um rendimento maior do que se estivessem empregados com carteira assinada) e o fato de que precisam pagar sozinhos por seus benefícios previdenciários (plano de saúde, férias, aposentadoria e FGTS).

No entendimento de Leite (2008), as exigências no mercado de trabalho estão maiores e, com isso, os trabalhadores começaram a pensar em novas maneiras de realizar suas atividades profissionais, pois a sobrevivência é um fato relevante a ser pensado. Pastore (1996) destaca o processo de flexibilização como necessário para o mercado de trabalho e as relações trabalhistas se expandirem. No Brasil, no entanto, a rigidez encontrada na Constituição de 1888 e nas leis trabalhistas, em termos de jornada de trabalho e remuneração, vem colocando limites a esse movimento.

Entende-se que os termos remuneração e salário não são sinônimos. O primeiro engloba diversas modalidades como os benefícios complementares (alimentação, plano de saúde, previdência privada etc), premiações e comissões, dentre outras modalidades. Já o segundo diz respeito apenas ao pagamento em dinheiro pelo serviço prestado. Robbins (2000) menciona que antigamente o salário era algo estável de acordo com a função das pessoas, levando em consideração o tempo de serviço prestado dentro da empresa e a hierarquia. $O$ objetivo atual das empresas é exatamente mudar a forma de pagamento para que este seja flexível e que a remuneração contemple modalidades diversas de retribuição.

Nota-se, portanto, que o crescimento em importância dos profissionais liberais, objeto de investigação do presente artigo se insere no contexto apresentado. Esse tipo de ocupação se transformou por meio do avanço da tecnologia, da ciência e as mudanças no mundo do trabalho. Hoje há um amplo leque de opções de trabalho e profissões a serem seguidas. Após os estudos realizados acerca de teorias que tratam das relações de trabalho, aqui resumidas, foi efetuada uma pesquisa de campo com os profissionais liberais (psicólogos) na SOBRAP/ JF para conhecer suas condições de trabalho e a satisfação e/ou insatisfação obtida, cujos resultados estão a seguir expostos.

\section{Resultados da pesquisa de campo}

O questionário aplicado nos profissionais pesquisados contou com dezoito questões estruturadas, utilizando-se a Escala de Likert e duas questões abertas.

O foco do questionário repousou na verificação da opinião dos respondentes sobre sua atuação como profissional liberal na instituição pesquisada, conforme já exposto. As questões estruturadas consistiram na apresentação de uma série de características do dia-a-dia profissional, verificando-se até que ponto, na percepção dos participantes, elas se manifestam em sua relação de trabalho com a SOBRAP/JF. A escolha das características pesquisadas foi efetuada com base na experiência de um dos pesquisadores que, conforme já informado, trabalha na instituição enfocada.

As 11 primeiras questões foram apresentadas sob duas perspectivas: a auto-avaliação, direcionada para que o participante manifestasse o quanto julga que incorpora a característica enfocada e a avaliação do grupo, que representa o quanto percebe tal característica manifesta no grupo de colegas. As demais sete questões envolveram apenas a auto-avaliação.

Solicitou-se que os participantes marcassem grau 1 quando discordassem fortemente que tal característica se manifesta no seu trabalho, grau 4 quando concordassem fortemente, ficando os graus 2 e 3 como níveis intermediários de concordância. A tabulação das respostas obtidas seguiu o roteiro a seguir exposto, tomando-se como exemplo a $1^{\text {a }}$ questão.

A primeira questão envolveu o seguinte fator: Execução das ações decididas pelo consenso do grupo. A Figura 1 revela os resultados obtidos na auto-avaliação. 
Figura 1: Execução das ações decididas pelo grupo - Auto-Avaliação

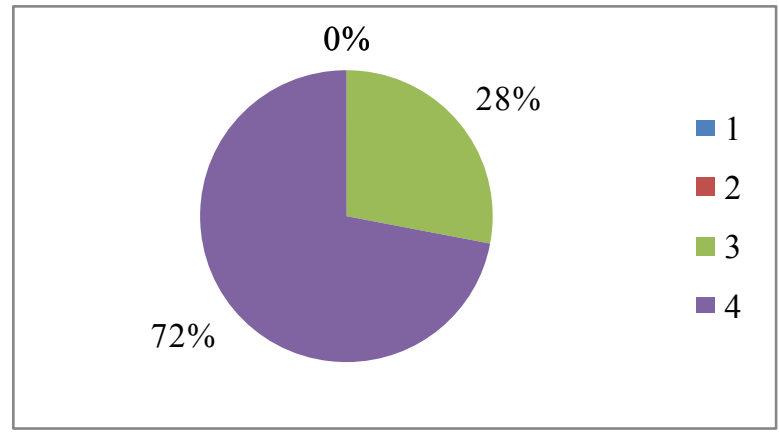

Fonte: os autores

A Figura 2 apresenta os resultados obtidos nessa mesma questão em relação à avaliação do grupo.

Figura 2: Execução das ações decididas pelo grupo - Auto Avaliação do Grupo

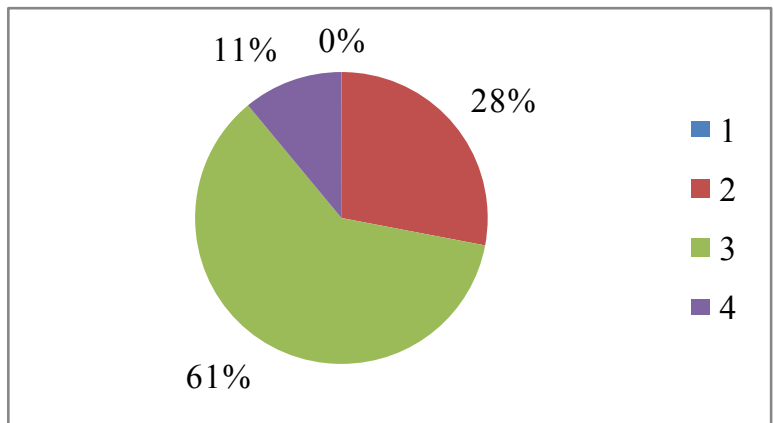

Fonte: os autores

Para favorecer a análise comparativa do grau de concordância dos respondentes com cada questão, foi utilizada a metodologia a seguir descrita, visando calcular o grau relativo, em uma escala de 0 a 100\%. Considerou-se que 100\% representariam a situação, hipotética, em que todos os respondentes assinalassem o grau máximo (4) na escala. Essa situação caracterizaria o maior grau possível de concordância com a afirmação feita. Na situação diametralmente oposta, $0 \%$ ocorreria se todos assinalassem o grau 1. Partindo-se desses parâmetros, primeiramente, foi efetuada a multiplicação das marcações obtidas em cada grau, seguindo a seguinte ponderação: 0 para cada marcação "1"; 1 para as marcações no grau "2"; 2 no grau "3" e 3 no grau " 4 ".

O somatório dos produtos obtidos com as multiplicações foi dividido pelo valor máximo que poderia ser alcançado (número total de respostas multiplicado pelo fator 3 ), achando-se, dessa forma, o resultado relativo, transformado em uma escala de 0 a 100. A Tabela 1 revela o cálculo efetuado na primeira questão, na dimensão de auto-avaliação. 
Tabela 1: Multiplicação das respostas da $1^{\text {a }}$ Questão - Auto-Avaliação

\begin{tabular}{|c|c|c|c|}
\hline Coluna & $\begin{array}{l}\text { Percentual de } \\
\text { Marcações }\end{array}$ & $\begin{array}{c}\text { Fator de } \\
\text { Multiplicação }\end{array}$ & Resultado \\
\hline $\begin{array}{l}---\frac{1}{2}-- \\
---\frac{3}{3}-- \\
---\frac{4}{4}--\end{array}$ & $\begin{array}{l}--\frac{0}{0}-- \\
---\frac{5}{5}-- \\
---\frac{13}{13}--\end{array}$ & $\begin{array}{l}--\frac{0}{-1}-- \\
---\frac{1}{2}-- \\
--\frac{2}{3}--\end{array}$ & $\begin{array}{l}0-0 \\
---\frac{0}{10}--- \\
--\frac{10}{39}---\end{array}$ \\
\hline Total & 18 & & 49 \\
\hline
\end{tabular}

Fonte: os autores

Conforme já exposto, o somatório dos produtos obtidos com as multiplicações foi dividido pelo valor máximo que poderia ser alcançado (número total de respostas multiplicado pelo fator 3). Tem-se, portanto, a divisão de 49 por 54 (total de respostas = 18 multiplicado por 3 = grau máximo). Obtém-se, então, 0,91, ou seja, $91 \%$. O resultado obtido representa o grau de percepção de que, em uma auto-avaliação, os respondentes julgam cumprir as decisões acordadas pelo grupo, em uma escala de 0 a 100.

Aplicando-se a mesma metodologia de tabulação dos dados às demais questões, encontraram-se os resultados expostos na Tabela 2, a seguir exposta: 
Tabela 2: Grau de concordância obtido em cada questão

\begin{tabular}{|c|c|c|}
\hline Questões & Auto-avaliação & Avaliação grupo \\
\hline 1 - Execução das ações decididas pelo consenso do grupo & $91 \%$ & $61 \%$ \\
\hline 2 - Interesse em debater idéias com os colegas & $76 \%$ & $57 \%$ \\
\hline $\begin{array}{l}3 \text { - Participação regular em atividades promovidas pela } \\
\text { SOBRAP/JF, como cursos, palestras e outros eventos }\end{array}$ & $67 \%$ & $30 \%$ \\
\hline $\begin{array}{l}4 \text { - Compartilhamento com os colegas das informações obtidas } \\
\text { em eventos }\end{array}$ & $50 \%$ & $39 \%$ \\
\hline $\begin{array}{l}5 \text { - Informação sobre o Estatuto e demais normas das } \\
\text { SOBRAP/JF }\end{array}$ & $81 \%$ & $67 \%$ \\
\hline 6 - Respeito por pontos de vista divergentes & $87 \%$ & $63 \%$ \\
\hline $\begin{array}{l}7 \text { - Bom relacionamento interpessoal, dispens ando a } \\
\text { intervenção da Coordenadora para solucionar conflitos }\end{array}$ & $91 \%$ & $80 \%$ \\
\hline 8 - Interes se em trabalhar em equipe & $70 \%$ & $56 \%$ \\
\hline 9 - Manutenção do local de trabalho organizado & $94 \%$ & $65 \%$ \\
\hline 10 - Pontualidade no atendimento aos pacientes & $94 \%$ & $71 \%$ \\
\hline $\begin{array}{l}11 \text { - Encaminhamento a outros colegas de pacientes que não } \\
\text { pode atender de modo adequado }\end{array}$ & $94 \%$ & $75 \%$ \\
\hline $\begin{array}{l}12 \text { - Sinto-me à vontade para discutir problemas com a } \\
\text { Coordenação }\end{array}$ & $81 \%$ & \\
\hline $\begin{array}{l}13 \text { - Sinto-me seguro em expres sar críticas e opiniões sobre a } \\
\text { SOBRAP/JF }\end{array}$ & $70 \%$ & \\
\hline 14 - Meu trabalho me proporciona realização profissional & $72 \%$ & \\
\hline $\begin{array}{l}15 \text { - Considero adequado o volume de trabalho que me é } \\
\text { confiado }\end{array}$ & $72 \%$ & \\
\hline $\begin{array}{l}16 \text { - Julgo importante contar com um supervis or na linha } \\
\text { teórica que atendo }\end{array}$ & $81 \%$ & \\
\hline 17 - De maneira geral, o preço das consultas é adequado & $53 \%$ & \\
\hline $\begin{array}{l}18 \text { - O valor repas sado à clínica por pacientes atendidos é } \\
\text { justo }\end{array}$ & $74 \%$ & \\
\hline
\end{tabular}

\section{Fonte: os autores}

De forma geral, é notório que da primeira questão até a $11^{\mathrm{a}}$, todas as porcentagens da auto-avaliação são maiores do que a avaliação do grupo. A média geral das auto-avaliações alcançou $78 \%$, contra apenas $60 \%$ das avaliações referentes ao grupo. Esse fato demonstra que os participantes da pesquisa possuem uma visão menos crítica sobre si próprios do que a que mantém em relação aos seus colegas.

Na primeira questão, houve, conforme revelado na tabela, uma elevada percepção de que o próprio respondente segue as decisões acordadas pelo grupo. Já em relação aos demais colegas, essa percepção não foi tão positiva, caindo de $91 \%$ de concordância na auto-avaliação para $61 \%$ na avaliação do grupo. Essa visão mais generosa em relação a si próprio do que em relação ao grupo pode ser explicada pela natural dificuldade que as pessoas têm de assumir seus próprios erros, especialmente no que tange à indisciplina em relação a procedimentos profissionais. O fato de a organização estar passando atualmente por muitas mudanças também pode contribuir para a percepção de que outras pessoas não estão agindo de forma adequada. 
Na questão 2, como observado na tabela, nota-se que $76 \%$ dos profissionais possuem interesse em debater ideias com os colegas, no referente a auto-avaliação. Quando o foco foi mudado para a avaliação do grupo, $57 \%$ acreditam que tal interesse existe por parte dos colegas. Não são conhecidas, na organização, situações em que uma pessoa tentou abrir canais de diálogo e foi rechaçada. Essa percepção pode, no entanto, ser consequência da forma como as mudanças recentemente introduzidas no modelo de gestão foram conduzidas. Houve reclamações por parte de vários profissionais de que a diretoria impôs tais mudanças sem abrir antes um canal de diálogo sobre o que seria feito.

$\mathrm{Na}$ questão 3, que versa sobre a participação regular em atividades promovidas pela SOBRAP/JF, como cursos, palestras e outros eventos, existe uma significativa discrepância entre a porcentagem da auto-avaliação, a saber $67 \%$, e a porcentagem obtida considerando a avaliação do grupo, $30 \%$. Ressalta-se que este último valor foi considerado o menor índice constatado nesta pesquisa de campo. Uma análise lógica dessa situação, mostra que está ocorrendo claramente uma visão distorcida. Se a maioria afirma que participar com regularidade desses eventos, como pode ser reduzida a participação do grupo como um todo? Ao contrário de outras questões que abordam aspectos mais subjetivos, a participação em eventos está relacionada a um dado objetivo: a frequência e não deveria, portanto, sofrer tamanha discrepância.

No ato de compartilhar com os colegas informações obtidas em eventos, como abordado na questão 4 , verifica-se que, ao avaliar a si próprio, a porcentagem obtida foi de $50 \%$, quanto o resultado da avaliação do grupo de trabalho, nota-se uma queda, pois este índice caiu para $39 \%$. A diferença não é tão grande quanto o verificado na questão anterior, embora mantenhase o padrão de se verificar uma visão mais favorável sobre si próprio do que sobre os colegas. Deve ser ressaltado que, em ambos os casos - auto-avaliação e avaliação do grupo, os índices alcançados são muito reduzidos. Essa deveria ser, portanto, uma preocupação por parte da gerência da organização, de modo a elevar a cooperação e a troca de conhecimentos dentro das equipes.

Na questão 5 , observa-se que $81 \%$ dos participantes julgam manter-se bem informados sobre o Estatuto e as demais normas da SOBRAP/JF, avaliaram o grupo como $67 \%$ pertencentes de tal conhecimento. A diferença, nesse caso, pode ser explicada pela natural dificuldade que cada um tem em avaliar essa situação em outras pessoas.

Sobre o respeito por pontos de vistas diferentes, enfatizado na questão 6 , percebe-se que $87 \%$ consideram praticar este ato e, ao avaliar o grupo, julgam menos presente essa atitude em seus colegas. Respeitar pontos de vista divergentes constitui um elemento essencial para a manutenção de um ambiente produtivo e de equipes sinérgicas. Preocupa, portanto, a percepção de que as outras pessoas não agem de forma adequada, manifestada pelo reduzido percentual de concordância alcançado em relação ao grupo. Mesmo o percentual em relação a si próprio tendo sido bem mais alto, ainda está longe do ideal. Respeitar opiniões diferentes da sua é uma exigência natural para um bom relacionamento interpessoal no trabalho. Nesse caso, $87 \%$ pode ser considerado um índice aquém do ideal.

$\mathrm{Na} 7^{\mathrm{a}}$ questão, $91 \%$ dos participantes da pesquisa concordaram ter um bom relacionamento interpessoal, dispensando a intervenção da Coordenadora para solucionar conflitos, $80 \%$ consideram este fato em uma visão grupal. É mais uma demonstração da percepção mais favorável sobre si próprio do que aquela mantida em relação ao grupo que cada pessoa apresentou na pesquisa. Pode-se inferir que os participantes desejam a intervenção da Coordenação para sanar problemas gerados ou administrados por terceiros, mas julgam não precisar da mesma quando se trata de seus próprios problemas.

A questão 8 diz respeito ao interesse em trabalhar em equipe, $80 \%$ dos profissionais possuem tal interesse, em relação a avaliação do grupo este índice caiu para $56 \%$. Essa 
é outra queda bem acentuada, portanto. Nesse caso, $80 \%$ de auto-avaliação não pode ser considerado um índice tão reduzido quanto, por exemplo, o que se verificou em relação ao respeito às opiniões divergentes. Tendo em vista a natureza do trabalho dos profissionais liberais, não é estranho que esse índice não seja próximo dos 100\%.

Como dito na questão 9 , sobre o fato de manter o local de trabalho organizado, $94 \%$ dos participantes consideram colaborar neste ponto, na avaliação do grupo $65 \%$ tem essa atitude no dia-a-dia. Tal situação revela que os participantes consideram que, de alguma forma, o local de trabalho deixa a desejar em relação à organização e que a culpa é muito mais de outras pessoas do que de si próprio.

$\mathrm{Na}$ décima questão, $94 \%$ dos profissionais consideram atender pontualmente os pacientes no horário marcado, porém na avaliação do grupo este número diminui para $71 \%$. Os profissionais podem perceber eventuais atrasos nos colegas quando verificam que os pacientes deles os estão aguardando na recepção. Essa verificação, no entanto, não é precisa.

A questão 11 trata sobre a realização do encaminhamento a outros colegas de pacientes que não pode atender de modo adequado. Para esta situação, 94\% mencionam executar este procedimento e verifica-se que na opinião dos profissionais $75 \%$ do grupo efetua tal prática. Essa é outra questão que, assim como ocorre em relação ao respeito às opiniões distintas, era de se esperar um percentual de concordância bem elevado. Na auto-avaliação, tal percentual ocorreu, de fato, mas na avaliação dos colegas foi reduzido, para o tipo de questão formulada. Trata-se, portanto, de uma visão negativa sobre a seriedade profissional dos colegas, pois atender um paciente sem estar devidamente qualificado atenta contra a ética.

A partir da questão número 12, houve um direcionamento apenas para a auto-avaliação dos participantes, obtendo-se os resultados a seguir destacados.

$\mathrm{Na}$ décima segunda questão, $81 \%$ se sentem à vontade para discutir problemas com a Coordenação. Esse é ainda um índice baixo. O ideal é que exista uma forte liberdade dos liderados para debater problemas com seus supervisores, ainda mais quando se trata de profissionais de nível superior, que possuem melhores condições de expressar suas ideias.

A questão 13 indagou se os profissionais sentem-se seguros para expressar críticas e opiniões sobre a SOBRAP/JF. Verifica-se que $70 \%$ dos participantes possuem segurança para expressar seu ponto de vista sobre a instituição. Esse também é um índice reduzido, que deve merecer a atenção dos gestores da organização, de modo a elevar a percepção de que se pode criticar a instituição, o que é fundamental para o desenvolvimento organizacional e a detecção de problemas.

Quando mencionado se o trabalho proporciona realização profissional, questão14, $72 \%$ consideram alcançar tal realização. Conforme destacado por diversas teorias de motivação para o trabalho, a realização profissional é complexa e depende muito mais do indivíduo do que do seu supervisor ou da organização na qual trabalha. Na ambiência organizacional contemporânea, é comum um grau elevado de estresse e de desmotivação. Tendo em vista esse fato, o índice alcançado não deve ser considerado muito reduzido.

$\mathrm{Na}$ décima quinta questão, $72 \%$ dos participantes consideram adequado o volume de trabalho confiado à sua prática profissional dentro da SOBRAP/JF. Há, portanto, uma percepção, em níveis significativos, de que a carga não é adequada. Tratando-se de profissionais que são remunerados proporcionalmente ao volume de atendimentos, essa percepção, no entanto, pode ser de que há menos trabalho do que poderiam ou gostariam de assumir. Seriam necessárias, no entanto, verificações complementares à que foi realizada, para confirmar se é essa a insatisfação ou se, ao contrário, há em alguns a percepção de sobrecarga no trabalho.

Sobre a importância de contar com um supervisor na linha teórica em que os psicólogos atendem seus pacientes, questão 16 , constatou-se que $81 \%$ dos participantes julgam este 
fato significativo. A existência dessa supervisão é recomendada pelo Conselho Regional de Psicologia, sendo considerada de fundamental importância. Como se verifica, no entanto, há pessoas que não reconhecem essa importância em grau elevado.

De maneira geral, o preço das consultas é adequado, neste aspecto verifica-se que $53 \%$ dos profissionais estão de acordo. Cabe ressaltar, que das questões direcionadas a autoavaliação, esta questão 17, foi a que atingiu menor porcentagem. Como os profissionais são remunerados com um percentual do que é cobrado dos pacientes, provavelmente eles entendem que o valor das consultas poderia ser maior, o que explicaria esse índice reduzido.

No tocante à abordagem se o valor repassado à clínica por paciente atendido é justo, dito na questão 18 , constata-se $74 \%$ de concordância por parte dos profissionais participantes da pesquisa. Por se tratar de um assunto normalmente polêmico, como a distribuição de recursos financeiros, o índice alcançado pode ser considerado bastante satisfatório.

As questões 19 e 20 foram realizadas de forma aberta, com o intuito de conhecer a opinião dos integrantes do Centro de Atendimento da SOBRAP/JF.

A questão 19 teve o seguinte enunciado: "Em relação às ocupações com carteira assinada, você julga que atuar como profissional liberal é: ( ) mais vantajoso ( ) menos vantajoso ( ) indiferente Por quê?". A figura 3 apresenta o percentual de marcação de cada opção de resposta.

Figura 3: Comparação - profissionais liberais x emprego tradicional

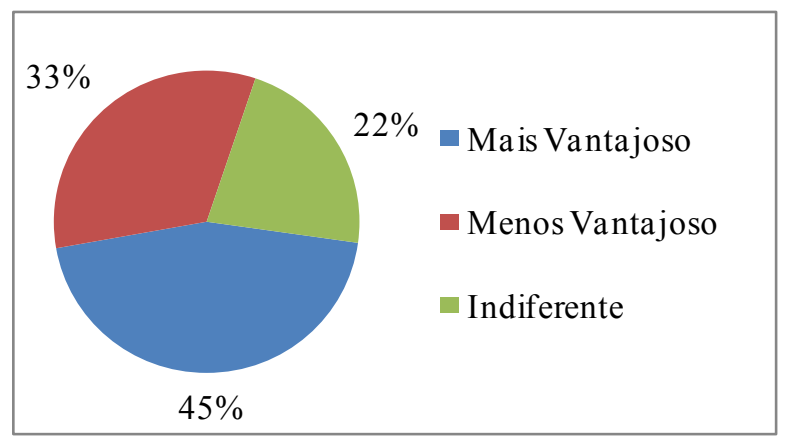

Fonte: os autores

Como pode ser observado através da figura exposta anteriormente, nota-se que $45 \%$ dos participantes consideram mais vantajoso atuar como profissional liberal. Assim, constatamse alguns pontos consideráveis na explicação destes participantes para a opção marcada, como: flexibilidade no horário de trabalho, renda financeira maior, autonomia, período de férias e dimensionamento do espaço profissional. Mesmo enxergando como mais vantajoso, alguns participantes destacaram desvantagens na atuação como profissional liberal, tais como: ausência de salário fixo, falta de estabilidade profissional, ausência do $13^{\circ}$ salário e aposentadoria.

Como demonstrado na figura, $33 \%$ dos participantes mencionaram como menos vantajosa a atuação enquanto profissional liberal e destacaram as seguintes justificativas: instabilidade profissional, carteira de trabalho não é assinada, férias incertas, ausência de $13^{\circ}$ salário, falta de auxílio para o transporte, FGTS, insegurança, direitos trabalhistas e aposentadoria do profissional liberal.

Observando ainda a figura 3, 22\% dos participantes da pesquisa que marcaram a opção indiferente, consideraram: tanto o profissional liberal quanto o profissional que tem carteira 
assinada possuem vantagens e desvantagens; o envolvimento profissional é o mesmo, independentemente se é liberal.

A $20^{\mathrm{a}}$ questão 20 teve o seguinte enunciado: "Que sugestões você daria para melhorar suas condições de trabalho na SOBRAP/JF?" Como dito anteriormente, esta questão foi aberta. Assim, o profissional pôde explanar seu ponto de vista, contribuindo por meio de sua sugestão para uma possível implementação de melhorias. Seguem o conjunto de sugestões apresentadas pelo grupo que participou da pesquisa:

Melhor esclarecimento sobre as normas de funcionamento da instituição, enfocando a parte de cursos.

Presença de uma assistente social, com o intuito de verificar a real situação socioeconômica dos pacientes através de uma triagem, haja vista, alguns pagam valores inferiores ao que realmente podem pagar.

As salas devem ser mantidas limpas, com o material organizado e completo.

Eventos com melhor organização para arrecadar dinheiro para a instituição.

Trabalho com os membros da SOBRAP/JF para melhorar o relacionamento e a integração das pessoas.

Além de estimular, os didatas devem possuir disponibilidade para auxiliar a construção de produções acadêmicas.

Maior transparência com relação às atitudes e decisões tomadas.

As mudanças realizadas atualmente trarão benefícios para a instituição em termos financeiros, na gestão e no relacionamento.

Estabelecer valor mínimo das sessões, pois a SOBRAP/JF não é mais considerada uma clínica social.

As exigências para poder atender no Centro de Atendimento (mensalidade da sociedade, supervisão e terapia) não são considerados preços "sociais". Assim, a ideia de clínica social não é coerente, não existe problema em querer ganhar dinheiro.

Não deve haver problema em querer ganhar dinheiro dentro por meio dos atendimentos realizados na instituição. Todos são profissionais formados e se aperfeiçoam cada vez mais nos estudos. Devem ser mais valorizados os atendimentos realizados.

Ter um local privado para os profissionais guardarem pastas e anotações pessoais (além do espaço destinado aos prontuários).

Mudança de local da sede, pois as escadas podem limitar o público alvo.

As reuniões devem ser realizadas com maior frequência.

Pedir doações de brinquedos e/ou jogos para melhorar a qualidade dos atendimentos.

A abertura de grupos de estudos teóricos e grupos de prática supervisionada.

Abrir a instituição para outros profissionais atuarem, como exemplo: fonoaudiólogos, assistentes sociais, advogados, psicopedagogos, dentre outros.

Todos integrantes da SOBRAP/JF deveriam se unir para expressar suas opiniões e insatisfações. Dessa maneira, uma estratégia de trabalho sólida seria construída, pois não existe solução pronta.

Nota-se, portanto, que os fatores que mereceram maior atenção, como exposto na pesquisa de campo, são: participação regular em eventos promovidos pela SOBRAP/JF, compartilhamento com os colegas de informações obtidas em eventos; adequação do preço das sessões e interesse em trabalhar em grupo. Além dessas situações, cabe verificar as 
sugestões apresentadas pelos participantes, com o intuito de implementá-las, se possível. Supõe-se que a observância das mesmas possa contribuir para que o ambiente de trabalho seja mais agradável e proporcione maior satisfação a seus integrantes.

\section{Conclusão}

Como observado no decorrer deste artigo, as relações de trabalho se modificaram ao longo do tempo de forma significativa, em especial após as mudanças observadas nas últimas décadas, com a emergência da chamada sociedade do conhecimento. Um dos aspectos nos quais vêm se observando mudanças mais intensas diz respeito ao tipo de vínculo mantido entre os trabalhadores e as organizações. O empregado com carteira assinada é subordinado a um superior, e a empresa assume o risco ou falha das atividades de trabalho. Já o profissional liberal realiza o trabalho por vontade própria e precisa arcar com seu próprio risco, mesmo trabalhando dentro de uma instituição. Até algumas décadas atrás, havia uma clara distinção entre essas duas modalidades. Os profissionais liberais, em sua quase totalidade, exerciam seu ofício sem nenhum vínculo com organizações. Médicos, advogados, contadores e outros mantinham seus escritórios independentes, sendo raros os que de alguma forma se vinculavam a instituições, a não ser que mantinham um vínculo tradicional de emprego.

A pesquisa, cujos resultados foram aqui apresentados, partiu da constatação de que essa situação mudou, havendo atualmente um crescente número de profissionais liberais que mantém vínculos com organizações sem que sejam, no entanto, empregados com carteira assinada. A elevação da concorrência e a necessidade de racionalização de custos representam, dentre outros fatores, motivos para essa mudança. Assim, o estudo direcionouse a uma instituição na qual se manifesta esse fenômeno, a SOBRAP, Regional Juiz de Fora, buscando responder a questão central já exposta: Quais os principais desafios enfrentados pelos profissionais liberais (psicólogos) do centro de atendimento da SOBRAP Regional Juiz de Fora?

Constatou-se que um dos desafios percebidos pelos profissionais pesquisados tem sido encontrar um preço adequado das consultas, que satisfaça seus interesses pessoais e, ao mesmo tempo, os da instituição. A dimensão financeira é naturalmente complexa, pois sua má gestão pode tornar, dependendo da política adotada, o trabalho pouco atrativo para os associados ou comprometer a política de preços, os gastos e, com consequência, a própria sobrevivência da organização. É fundamental que os parâmetros e as regras a serem observadas estejam bem alinhadas desde o início das relações entre cada profissional e a instituição, de modo a que não sejam geradas divergências de expectativas. Devem ser pactuadas também formas de se promover a revisão periódica dos valores, de modo a mantêlos atualizados frente à inflação e a eventuais mudanças no mercado.

Outro aspecto que mereceu destaque por parte dos entrevistados foi a viabilidade da participação regular em eventos promovidos pela instituição. Nas relações tradicionais de emprego, o tempo destinado a tais eventos faz parte, em geral, da jornada de trabalho. Assim quem investe na realização de cursos e atividades similares é basicamente a organização, que disponibiliza parte do tempo que seria destinado às atividades produtivas. No caso em estudo, todavia, quando estão em eventos de capacitação, são os próprios participantes que arcam com ônus de não estarem produzindo ou precisam abrir mão de horários de descanso e lazer. Nesse aspecto também se revela de grande importância a clareza das regras, incluindo a regularidade prevista para a realização das atividades em questão, desde o momento em que o profissional ingressa na instituição. Não se pode negar a importância da capacitação e deve ficar claro que ela se faz necessária para manter a qualidade dos serviços prestados, em especial a unidade entre os profissionais associados à organização. É também recomendável que o tempo dedicado a esses eventos seja otimizado, por meio de uma correta definição 
de prioridades e da condução objetiva das reuniões. Conforme destacado, os profissionais participantes percebem como baixo o interesse dos colegas em tais atividades, sinalizando que alguma providência a respeito precisa ser adotada.

O compartilhamento com os colegas de informações obtidas em eventos foi outro ponto destacado como relevante. A despeito de não constituírem uma equipe tradicional, subordinada diretamente a um gerente, os profissionais precisam ter consciência de que somente quando se integram de fato em torno de conhecimentos, valores e posturas comuns é que vão manter uma identidade institucional efetiva. Sem que tal identidade seja fortalecida, a organização se enfraquece, gerando consequências negativas para os próprios associados. Trata-se, portanto, de uma prática que precisa ser fomentada pela organização e valorizada pelos associados, sendo estimulada por meio de políticas e práticas adequadas. Os reduzidos graus de interesse verificados nesse aspecto, tanto na auto-avaliação dos profissionais quanto na sua percepção sobre os colegas, deve merecer a atenção da instituição, buscando-se formas de modificar a situação.

O interesse em trabalhar em grupo é outro aspecto que merece destaque. Ainda que os profissionais em questão atuem de forma individual com seus pacientes, determinados tratamentos podem requerer esforços articulados. Além disso, o trabalho em equipe pode se manifestar na forma de debates, grupos de estudo e troca de informações. A expressiva maioria manifestou interesse em articular-se com o grupo. Verificou-se, no entanto, uma visão pessimista nesse aspecto, incluindo fatores tão importantes como, por exemplo, o respeito à opinião dos outros, que foi classificado como muito baixo, em especial quando se avaliou a postura dos colegas.

No que tange ao relacionamento com seus supervisores, os resultados obtidos, como destacado, não foram ideais. Nota-se uma certa insegurança em discutir problemas e expressar críticas. Tratando-se de uma relação distinta da subordinação direta tradicional entre patrões e empregados, seria de se esperar a manifestação de uma maior liberdade de expressão. Esse é mais um aspecto que precisa ser considerado pela instituição, portanto.

A despeito dos problemas identificados, cabe ressaltar que a maioria dos participantes considera mais vantajoso desenvolver seu trabalho como profissional liberal, sem estabelecer vínculo empregatício com a instituição. Justificaram essa escolha por meio da satisfação obtida pelos seguintes aspectos: flexibilidade no horário de trabalho, renda financeira maior, autonomia, período de férias e dimensionamento do espaço profissional. Os elevados graus de realização profissional e satisfação com a carga de trabalho representam exemplos de fatores que sinalizaram essa preferência. Porém, mesmo mencionando que esta forma de trabalho é a que melhor atende suas necessidades, ressalvas foram feitas em termos de desvantagens: ausência de salário fixo, falta de estabilidade profissional, ausência do $13^{\circ}$ salário e aposentadoria. Nada, portanto, que não seja previamente conhecido de quem opta por essa modalidade para o exercício de sua profissão.

Conclui-se, por fim, através das sugestões realizadas pelos participantes que o ambiente de trabalho pode ser modificado, de modo a atender satisfatoriamente os profissionais, fazendo com que o nível do trabalho desempenhado tenda a melhorar. Os subsídios aqui apresentados poderão ser analisados pela direção da organização, com vistas à adoção de mudanças que possam fortalecer os aspectos positivos e minimizar os negativos. Sugere-se, no entanto, que sejam realizados periodicamente estudos similares a este para observar se a evolução dos aspectos enfocados, que, como destacado, podem se alterar em função de diversos fatores. 


\section{Referências}

BRASIL Constituição da República Federativa do Brasil de 1888. 2011. Disponível em: <http://www.planalto.gov.br/ccivil_03/constituicao/constitui\%C3\%A7ao.htm>. Acesso em: 05 Setembro 2011.

DINIZ, Maria Helena. Curso de Direito Civil Brasileiro: Teoria das obrigações contratuais e extracontratuais. $18^{\circ}$ ed. São Paulo: Saraiva, 2003.

GIL, Antonio Carlos. Como elaborar projetos de pesquisa. 4 ed. São Paulo: Atlas, 2002.

GODOY, A. S. Introdução à pesquisa qualitativa e suas possibilidades. In: Revista de Administração de Empresas. Vol. 35, n² 2. São Paulo: abril 1995, p. 57-63.

HITT, Michael A.; MILLER, C. Chet \& COLELLA, Adrienne. Comportamento Organizacional: uma abordagem estratégica. Rio de Janeiro: LCT, 2007.

HOBSBAWM, Eric J. Da Revolução Industrial Inglesa ao Imperialismo. 5 ed. Rio de Janeiro: Forense Universitária, 2009.

LEITE, Ana Cláudia de Oliveira. A Flexibilidade nas Relações de Trabalho e o Cooperativismo. Revista de Ciências Gerenciais, Vol. XII No 14, Anhanguera Educacional S. A., 22 de setembro 2008. Disponível em: <http://sare.unianhanguera.edu.br/index.php/rcger/ article/viewFile/113/111>. Acesso em: 08 Setembro, 2001.

MARCONI, M. D. A.; LAKATOS, E. M. Técnicas de pesquisa: planejamento e execução de pesquisas, amostragens e técnicas de pesquisas, elaboração, análise e interpretação de dados. 3 ed. São Paulo: Atlas, 1996.

MARTINS, G. Estudo de caso: uma estratégia de pesquisa. São Paulo: Atlas, 2006. 2000.

MASI, Domenico de. A Sociedade Pós-Industrial. 3 ed. São Paulo: Senac São Paulo,

MINAYO, M. C. de S. Pesquisa social: teoria, método e criatividade. 22 ed. Rio de Janeiro: Vozes, 2003.

NETO, Benedito R. M. Marx, Taylor e Ford: as forças produtivas em discussão. 2 ed. São Paulo: Editora Brasiliense, 1991.

NUNES, Luiz Antonio Rizzato. Comentários ao Código de Defesa do Consumidor: Direito material. São Paulo: Saraiva, 2000.

PASSOS, Carlos Artur Krüger. Novos Modelos de Gestão e as Informações. Rio de Janeiro: Editora Campus, 1999.

PASTORE, José. Flexibilização dos Mercados de Trabalho e Contratação Coletiva. São Paulo: LTR, 1996.

PRUX, Oscar Ivan. Responsabilidade Civil do Profissional Liberal no Código de Defesa do Consumidor. Belo Horizonte: Del Rey, 1998. 2000.

ROBBINS, Stephen P. Administração: mudanças e perspectivas. São Paulo: Saraiva,

RODRIGUEZ y RODRIGUEZ, Matus Vicente. Gestão do conhecimento: reinventando a empresa para uma sociedade baseada em valores intangíveis. Rio de Janeiro: IBPI Press, 2001.

RUDIO, Franz Victor. Introdução ao projeto de pesquisa científica. 22 ed. Rio de Janeiro: Vozes, 1998.

SOBRAP Regional Juiz de Fora. Desenvolvido por Leonardo Aguiar. Disponível em: <http://www.sobrap.org/>. Acesso em: 18 agosto 2011. 
SÜSSEKIND, Arnaldo. Da Relação de Trabalho. Rev. TST. Brasília, Vol. 75, № 4, Out/Dez 2009. Disponível em: <http://www.tst.gov.br/Ssedoc/PaginadaBiblioteca/revistadotst/Rev_75/ Rev_75_4/sussekindarnaldo.pdf>. Acesso em: 05 Setembro 2011.

VASCONCELOS, Fernando Antônio de. Responsabilidade do Profissional Liberal nas Relações de Consumo. Curitiba: Juruá, 2003.

VERGARA, Sylvia Constant. Projetos e relatórios de pesquisa em administração. 10 ed. São Paulo: Atlas, 2009.

ZABOT, J. B. M.; ARDIGO, J. D. \& SALM, J. F. Os Desafios Gerenciais das Organizações do Conhecimento. Gestão: Revista de Administração e Gerência. ESAG/ UDESC, Florianópolis, Vol. 1, No 1, Jun. 2001, p. 85-96. 